\title{
Can ABC Lead to Sustained 123? \\ The Medium-Term Effects of a Technology-Enhanced Adult Education Program
}

\author{
Jenny C. Aker and Christopher Ksoll ${ }^{*}$
}

September 2017

\begin{abstract}
Can information technology preserve the short-term learning gains associated with adult education programs? This study estimates the medium-term impacts of a mobile phone module (Project ABC) that was added to a standard adult education curriculum, and for which there were significant short-term impacts on educational outcomes. Two years after the end of the program, students in ABC villages had reading scores that were significantly higher than those in standard adult education classes, and women and younger students were better able to decode numbers. This can be partially attributed to more active mobile phone usage in $\mathrm{ABC}$ villages. Households in $\mathrm{ABC}$ villages also were more likely to own durable assets, had lower levels of food security and were more likely to save. Overall, these results suggest that short-term learning gains associated with technology can persist, especially if students have the opportunity to practice with that technology after the end of classes.
\end{abstract}

Keywords: Education; Information Technology; Niger

\footnotetext{
*Jenny C. Aker, Department of Economics and The Fletcher School, Tufts University, 160 Packard Avenue, Medford, MA 02155; Jenny.Aker@tufts.edu. Christopher Ksoll, Mathematica Policy Research; Christopher.ksoll@gmail.com.. We thank Catholic Relief Services (CRS) Niger for their support in implementing the initial program. We are grateful for financial support from the Hitachi Center at the Fletcher School and the World Bank. We are grateful for comments from seminar participants at Tufts University and the University of California-Irvine. All errors are our own.
} 


\section{Introduction}

The question of whether educational gains persist is of interest to academics and policymakers alike. The belief that educational investments will lead to sustained improvements in learning, and hence in improvements in adults' living standards, underlies many education programs. Yet despite improvements in primary school enrolment since the 1990s, there have been limited improvements in learning outcomes. This, as well as the widespread growth of information technology in many developing countries, has been the rationale for using "technology-assisted" instruction, in the hopes that such technology would lead to improvements in learning in the short- and long-term.

Existing research on the impact of technology-assisted learning has mixed results, with positive impacts of computer-assisted instruction on learning in India and China (Banerjee et al 2007, Linden 2008, Lai et al 2011, 2013, Mo et al 2014, Deshpande et al 2017) to no effect in Colombia, Peru and the U.S. (Barrera-Osorio and Linden 2009, Beuermann et al. 2013, Fairlie and Robinson 2014). Focusing on mobile phone technology and adult learning, Aker et al (2012) find that a mobile phone-enhanced adult education program in Niger significantly improved adults' reading and math z-scores in the short-term. Similarly, Aker et al (2016) find that a mobile phone-based adult education intervention in Los Angeles significantly improved adults' reading levels in Spanish over a four-month period.

While there is significant research showing that learning gains from primary education fall rapidly (ie, Kane and Staiger 2008, Jacob, Lefgren, and Sims 2010, Rothstein 2010, Glewwe et al 2010, Banerjee et al. 2007), there are few studies in the area of technology-assisted learning. One notable exception is that of Banerjee et al 
(2007), who find that from a computer-assisted education program fell rapidly within one year of the program (Banerjee et al 2007). Yet, to our knowledge, there is little evidence in economics on the impact of technology-assisted instruction on adults' learning outcomes in the medium-term, nor on the impact of such programs on other indicators of well-being.

In prior work, Aker et al (2012) measured the impact of a mobile phone-assisted module $(\mathrm{ABC})$ as part of an adult education program, finding that simply learning how to use a mobile phone increased adults reading and math z-scores by .19-.25 s.d., with persistent effects seven months after the program. The impacts were similar by gender and age, although relatively stronger in one region, and were primarily driven by students' increased use of the mobile phone during and outside of class. While overall learning levels were quite low - students were primarily able to recognize words and solve simple math problems - they were sufficient to operate the mobile phone.

Using data collected two years after the end of the experiment in Niger (Aker et al 2012), this paper assesses whether the short-term learning gains observed in the ABC program persist several years after the program, as well as translate into other improvements in socio-economic outcomes. We find that the short-term reading gains from the $\mathrm{ABC}$ program persist several years' later: Students in $\mathrm{ABC}$ villages were 7 percentage points more likely to be able to read words and had reading z-scores that were .15 s.d. higher than those in non-ABC villages, with similar effects for men and women. Average math scores in $\mathrm{ABC}$ villages are the same as those in the standard adult education villages after the program, with differential effects by gender and age. The additional mobile phone instruction was also associated with improvements in other 
socio-economic outcomes: $\mathrm{ABC}$ households engaged in more diverse income-generating strategies, were more likely to own a durable asset, had improved food security, were more likely to produce and sell marginal cash crops and were more likely to save. Yet we are unable to disentangle whether these medium-term impacts on socio-economic outcomes are primarily due to improvements in learning, improved access to information by better manipulation of mobile phones, or some combination of the two.

Overall, this paper contributes to the existing literature on the medium-term effects on education programs. While there are a number of studies in this area, many of these are for primary education programs, thereby measuring skills acquisition and labor market outcomes in adulthood (Jacob et al 2010, Duflo 2003, Evans et al 2014). There is a smaller subset of papers that assess the impact of adult education programs on learning (Okech et al 2001, Royer et al 2004, Ortega et al 2008, Banerji et al 2016, Deshpande et al 2017) or welfare (Blunch and Portner 2011). Yet to our knowledge, only one of these studies focuses on adult education programs with a technology component (Deshpande et al 2017), and none of them assess whether short-term learning gains persist after the program.

The rest of this paper proceeds as follows. Section II describes the research design, whereas Section III outlines the data and estimation strategy. Section IV presents the core results, including the results on well-being and mechanisms, whereas Section V presents the alternative explanations. Section VI concludes. 


\section{Research Design}

The original experiment used in this paper is described in detail in Aker et al (2012), and is summarized here. ${ }^{1}$ Starting in February 2009, an international non-governmental organization, Catholic Relief Services, implemented an adult education program in two regions of Niger. The program provided eight months of literacy and numeracy instruction to adults in 134 villages. The course cycle was for two years, and classes were held between February and June of each year, with a break between June and January due to the agricultural planting season. Classes were taught in the indigenous language of the village and were held five days per week for three hours per day. Each village had two literacy classes (separated by gender), with twenty-five students per class. Each class was taught by a community literacy teacher, with two teachers per village (Aker et al 2012).

The mobile phone intervention $(\mathrm{ABC})$ was a module added to the basic adult education program. Students in $\mathrm{ABC}$ and non- $\mathrm{ABC}$ villages followed the same curriculum, but students in $\mathrm{ABC}$ villages also learned how to use a simple mobile phone (Aker et al 2012). In addition, a mobile phone was provided to groups of literacy participants in $\mathrm{ABC}$ villages, with one mobile phone per group of five people. The mobile phone module was introduced three months after the start of the adult education program. Teachers in $\mathrm{ABC}$ villages were instructed to teach the mobile phone module for approximately one hour during the weekly review class (Aker et al 2012)

The primary sample for the original experiment was 113 villages in two regions of Niger. The original experiment stratified villages by geographic divisions, and then

\footnotetext{
${ }^{1}$ The text in this section is paraphrased heavily from the original research design section of the Aker et al (2012) paper.
} 
randomly assigned villages to a cohort (to start adult education classes in 2009 or 2010) and either the basic (non-ABC) or the basic plus mobile-phone intervention $(\mathrm{ABC})$. Those in the 2009 cohort ended their course in 2010, and those in the 2010 cohort ended in 2011.

Within each village, eligible students were identified for both cohorts during the baseline. Individuals had to be illiterate, willing to participate in the program and a member of either a formal or informal village-level producers' association. If there were more than fifty eligible applicants in a village, students were randomly chosen from among all eligible applicants in a public lottery.

As there was no pure control group in the original experiment, this paper estimates the causal effect of the $\mathrm{ABC}$ intervention as compared to the standard adult education intervention. As a result, we cannot estimate the causal impact of the adult education program, and therefore cannot answer questions pertaining to the returns to adult education.

\section{Data and Estimation Strategy}

\section{A. Data}

The data we use in this paper come from two primary sources. First, we administered math and reading tests and use these to measure the impact of the program on learning outcomes several years after the program. Second, we conducted surveys about student and household characteristics. Before presenting our estimation strategy, we discuss each of these data sources in detail.

In 2013, two years after the end of the original program, we returned to one region (Dosso) to collect test score and household data. The focus on one region was 
purposeful: While there was not a statistically significant difference of the impact of the $\mathrm{ABC}$ program by region in the original paper, the coefficients were larger in magnitude when focusing on the Dosso region (Aker et al 2012). As a result, our data collection efforts in 2013 focused solely on this region. Using the original list of all students in each village from 2009, we confirmed students' presence in the village in 2013. Among those present, we stratified by gender and chose a random sample of 16 households per village.

In our previous work, we assessed learning using the Ministry of Non-Formal Education's battery of tests. For this follow-up study, we used USAID's Early Grade Reading Assessment (EGRA) and Early Grade Math Assessment (EGMA) tests. EGRA is a series of timed tests that measure basic foundational skills for literacy acquisition: recognizing letters, reading simple words and phrases and reading comprehension (Dubeck and Gove 2015). Each task ranges from 60-180 seconds; if the person misses four answers in a row, the exercise is stopped. EGMA measures basic foundational skills for math acquisition: number recognition, comparing quantities, word problems, addition, subtraction, multiplication and division (Reubens 2009).

The EGRA and EGMA tests were our preferred survey instruments, as compared with the Ministry's untimed tests, for two reasons. First, most adult education programs are criticized for high rates of skills' depreciation. Yet skills' depreciation may be in part due to the low reading levels achieved by the end of traditional adult education programs, which cannot be easily captured in untimed tests. For example, the short-term memory required to store deciphered material is brief, lasting 12 seconds and storing 7 items (Abadzi 2003). Thus, "Neoliterates must read a word in about 1-1.5 second (45-60 words 
per minute) in order to understand a sentence within 12 seconds (Abadzi 2003)."² Thus, the EGRA timed tests allow us to determine whether participants in adult education classes are attaining the threshold required for sustained literacy acquisition. Second, the tests offer a great deal of precision in terms of measuring the skills that contribute to reading and math acquisition, capturing more nuanced levels of variation in learning (Dubeck and Gove 2015). While this makes it difficult for us to directly compare learning levels between 2011 and 2013, the EGRA tests can be easily converted into the Ministry's reading levels. This mapping is more challenging for the math tests.

In addition to the reading and math tests, students participated in a household survey, which asked questions about socio-demographic characteristics, assets, agricultural production and marketing, livestock production and food security. These data are used to measure the longer-term impacts of the program on different indicators household assets, agricultural and savings behavior, and food security status.

Attrition is a concern in most studies, especially those that return after the end of the program and amongst populations who engage in seasonal migration. Table A1 formally tests whether there is differential attrition by ABC status for the follow-up survey rounds in 2013. The rate of attrition in the non-ABC villages was 5 percent, with the same rates of attrition in the $\mathrm{ABC}$ villages. The primary reasons for attrition were migration, illness and death, although these did not differ by ABC status or other sociodemographic characteristics, such as gender or age (Table A2). Thus, this suggests that attrition is not a primary concern in our context.

\footnotetext{
${ }^{2}$ This speed corresponds to oral-reading U.S. norms for first grade children. However, this is often not attained in literacy classes. For example, studies in Burkina Faso indicate that most literacy graduates need 2.2 seconds to read a word and are correct only 80-87 percent of the time (Abadzi 2003).
} 


\section{B. Balance of Time-Invariant Characteristics}

The original experiment yielded groups that were similar along observable characteristics prior to the program (Aker et al 2012). Table 1A shows this balance from the original experiment for the Dosso region, the focus of this paper. Since the program occurred between 2009 and 2011, we would expect time-varying characteristics to change as a result of the program. However, we can test for whether the original experimental balance remains among our new sample by testing for the equality of means for time-invariant characteristics between $\mathrm{ABC}$ and non-ABC villages. Table $1 \mathrm{~B}$ presents these results. Overall, there are no statistically significant differences in timeinvariant characteristics between the $\mathrm{ABC}$ and non- $\mathrm{ABC}$ villages, with the exception of marital status; women in $\mathrm{ABC}$ villages were 3 percentage points less likely to be married than their non-ABC counterparts, with a statistically significant difference at the 10 percent level.

\section{Estimation Strategy}

In order to measure the medium-term impacts of the $\mathrm{ABC}$ program, we use the following estimation strategy:

$$
\text { test }_{i c v}=\alpha+\beta_{1} A B C_{v}+\mathbf{X}_{i} \gamma+\delta \text { cohort }_{v}+\theta_{R}+\varepsilon_{i v}
$$

Where test $_{i c v}$ is the Early Grade Reading Assessment (EGRA) or Early Grade Math Assessment (EGMA) score attained by student $i$ two years after the program, $A B C_{v}$ is an indicator variable for whether individual $i$ was assigned to the $\mathrm{ABC}$ or non-ABC intervention between 2009 and 2011, $\theta_{R}$ are fixed effects that indicate the randomization strata, $\mathbf{X}_{i 0}$ is a vector of student time-invariant covariates, primarily gender, and cohort $_{v}$ is the year the village started in the adult education program (equal to 1 if 2010 cohort), 
since the program was phased in over time. We cluster standard errors at the village level and correct for heteroscedasticity.

A key assumption in the identification of the medium-term treatment effect is that the independence assumption holds. This assumption appears to be valid, as presented in the Table 1. Additional threats to the validity of the treatment effect are discussed in Section V.

\section{Results}

\section{A. Medium-Term Effects of the Program}

Table 3A presents the results of equation (1) on reading scores two years' after the end of the program. Overall, the results suggest that the short-term learning gains persisted: $\mathrm{ABC}$ students were 8 percentage points more likely to be able to read any word and were able to correctly read two more words as compared to their non-ABC counterparts, with a statistically significant effect at the 5 percent level (Panel A). These results are also robust to the use of reading z-scores: $\mathrm{ABC}$ students achieved reading levels that were .15 s.d. higher as compared to non-ABC students, with a statistically significant effect at the 5 percent level (Column 3). While ABC students reading automaticity and comprehension were also higher as compared to those in non- $\mathrm{ABC}$ villages, these effects are not statistically significant at conventional levels (Columns 4 and 5). Although the EGRA tests do not map perfectly to the previous Ministry tests, the results are robust to this mapping: students in $\mathrm{ABC}$ villages read at a level that was half a point higher than those in non-ABC villages two years after the program, a $25 \%$ increase. 
Similar to the short-term effects of the program, there are no differential effects by gender or age (Panels B and C). ${ }^{3}$

Table 3B shows the results of the estimation of equation (1) for math scores. While average math scores - including number identification, simple addition and subtraction and a composite math score - are higher in $\mathrm{ABC}$ villages, none of these differences are statistically significant at conventional levels. Yet the heterogeneous results by gender and age suggest that the $\mathrm{ABC}$ program enabled women and younger students to continue to correctly identify numbers several years after the program (Panels B and C, Columns 1 and 2). In particular, for those students younger than 39 years of age, the $\mathrm{ABC}$ program helped them to retain their number identification and general math skills (Panel C, Column 5).

In our previous work, the $\mathrm{ABC}$ program increased average math scores by .25 s.d. relative to the standard adult education program in the short-term, with no differential effects by gender or age. What could potentially explain the absence of an average effect several years after the program? First, ABC students' math skills could have depreciated during this time, thus returning to non- $\mathrm{ABC}$ levels at the end of the program. This is possible, as, other than identifying numbers, mobile phone usage - which was the crux of the $\mathrm{ABC}$ program -- would not necessarily assist students in using and hence retaining more complicated mathematical operations, such as addition and subtraction. In addition, our previous work showed strong rates of depreciation in learning six months' after the

\footnotetext{
${ }^{3}$ While not shown, there are also no differential effects of the ABC program by language (Hausa or Zarma); this is particularly relevant for adult education programs, as the language's transparency can affect how easy it is for adults to learn and retain reading skills.
} 
program, and the $\mathrm{ABC}$ program was not effective in reducing the rate of depreciation (Aker et al 2012). ${ }^{4}$

An alternative explanation for the absence of average effects on math scores is the way in which the math tests were administered in 2013. In particular, the EGRA tests allowed for addition and subtraction tasks to be completed verbally. Hence, the 2013 tests did not capture $\mathrm{ABC}$ students' ability to decode written mathematical problems, as was the case in 2011 math tests from our previous work.

\section{B. Skills Depreciation after the Program}

The results in Tables 3A and 3B suggest that the additional skills that $\mathrm{ABC}$ students initially attained became smaller over time, especially for math. This could be due to the typical depreciation observed in adult education programs (Abadzi 2003). ${ }^{5}$ Yet simply comparing math and reading test score levels after the program ignores students' learning at the end of the program, which should be highly correlated with persistence.

A common method to account for persistence is to use the value-added model - either restricted or lagged - that controls for the previous period's test scores. ${ }^{6}$ Andrabi et al (2011) show that a standard estimation of this model - especially when previous test scores are endogenous - yields biased estimates of both the persistence coefficient and

\footnotetext{
${ }^{4}$ While non-ABC students could have also improved their math skills after the end of the program, thereby "catching up" to ABC students, this seems unlikely, as there were not additional or new adult education programs in these villages between 2011 and 2013.

${ }^{5} \mathrm{An}$ interesting question is, however, whether the loss in learning is smaller or larger for $\mathrm{ABC}$ learners relative to what would be expected. This could be because students continue to use their skills more often or even continue expanding their skillset due to interactions with the phone.

${ }^{6}$ In 2011, we used Ministry tests, which mapped students' learning gains from 0 to 7, based upon a series of 6 tasks. In 2013, the EGRA and EGMA tests involved a series of timed tasks. While it is straightforward to map the 2013 reading test scores to the 2011 reading tests, this is less straightforward for math. Nevertheless, there are some tasks that are similar across both tests, which allows us to map the 2013 results to the 2011 levels.
} 
the treatment effect. In order to correct for this bias, they suggest using panel data methods over three data collection rounds.

In this paper, we have data from two periods - the program endline data (in 2011) and the follow-up data (in 2013), and thus cannot use the panel data methods suggested by Andrabi et al (2011). While data are also available from the original baseline conducted in 2009, these are not informative, as almost all baseline reading and math levels were zero. Thus, to test whether ABC slowed the loss in skills, we use the 2011 and 2013 data from the same sample of students in the following value-added specification: ${ }^{7}$

$$
\text { test }_{i c v 2013}=\alpha+\beta_{1} A B C_{v}+\beta_{2} \text { test }_{i c v 2011}+\mathrm{X}_{i} \gamma+\delta \text { cohort }_{v}+\theta_{R}+\varepsilon_{i v}
$$

where $\beta_{1}$ is the treatment effect and $\beta_{2}$ is the persistence coefficient. $\beta_{1}$ is the mediumterm effect of the ABC program, accounting for the expected depreciation.

Since the 2011 test scores were affected positively by the ABC program, both student-specific heterogeneity in learning and measurement error will bias $\beta_{2}$, thereby yielding biased estimates in both the treatment and persistence coefficients. To partially address this bias, we use the control function approach, similar to that outlined by Petrin and Train (2002). At the first stage, we regress 2011 test scores on village-level fixed effects, which also captures the $\mathrm{ABC}$ treatment variable, in the following specification:

$$
\text { test }_{i c v 2011}=\theta_{V}+u_{i v}
$$

At the second stage, we include the estimated residual from the first stage as a covariate in the following specification:

\footnotetext{
${ }^{7}$ There are two primary value-added specifications in the education literature: the restricted value-added model and the lagged value-added model. The former assumes that "lagged achievement contributes cumulatively without loss to future achievement", whereas the latter allows the contribution of previous achievement may decay (Andrabi et al 2011). A variety of specifications using the lagged value-added model suggest a depreciation coefficient of .6 (Andrabi et al 2011).
} 


$$
\text { test }_{i c v 2013}=\alpha+\beta_{1} A B C+\delta \hat{u}_{i v 2011}+\varepsilon_{i v}^{8}
$$

The above approach corrects for any potential bias in the treatment effect, but not for the persistence effect. While this is potentially problematic, Andrabi et al. (2011) find that the bias from heterogeneity is larger than the bias from measurement error. This may also be the case for the tests studied here, which are designed to measure key building blocks of literacy and of numeracy. Omitted heterogeneity leads to an overestimate in the persistence coefficient and an underestimate of the treatment effect. In our case, this would suggest that the impacts of the ABC program on skills retention are likely to be underestimated. Nevertheless, we recognize that this approach does not fully remove all potential selection bias induced from the value-added specification.

Table 4 shows the results of these specifications, first using the standard OLS specification in equation (2) (Panel A). Using standard methods, reading and math test scores are higher in $\mathrm{ABC}$ villages than non- $\mathrm{ABC}$ villages two years after the program after controlling for prior achievement, although only one of these coefficients is statistically significant at conventional levels. Yet there is differential persistence: the coefficient on the lagged dependent variable ranges from .30 (for math) to .76 (for reading).

Panel B attempts to correct for potential bias in the treatment effect by using the control function approach outlined above. Unsurprisingly, the persistence coefficients remain fairly stable - ranging between .30 and .73 . Nevertheless, the coefficients on the $\mathrm{ABC}$ variable are positive and statistically significant for reading, and positive but not statistically significant for math (with a p-value of .16). This supports the results

${ }^{8}$ Following Petrin and Train, we first use robust standard errors clustered at the village level. We then draw bootstrap samples, identifying how much the estimated coefficient varies due to the estimation of village fixed effects in the first stage. We then add this to the estimated variance from the clustering. 
provided in Table 3, suggesting that the impacts of the ABC program on learning outcomes persisted, especially for reading, two years after the program.

\section{Mechanisms}

What are the mechanisms through which the short-term learning gains in learning persisted? And can these gains be attributed to learning or continued practice with the mobile phone? In Aker et al (2012), the authors found that the primary mechanism for short-term learning gains was increased mobile phone usage: students living in $\mathrm{ABC}$ villages were more likely to use the mobile phone in more active ways, both during classes and seven months after the end of the program. Table 5 suggests that this practice continued after the end of the program. While the ABC program was not associated with a higher likelihood of mobile phone usage or increased spending on mobile phone airtime, $\mathrm{ABC}$ students used mobile phones in more active ways two years after the program. They were more likely to make calls, write and receive SMS and send and receive airtime as compared with their non-ABC counterparts. Yet this did not translate into changes in students' social or professional communication: ABC students were equally likely to talk with relatives or business contacts as their non-ABC counterparts, suggesting that perhaps they increased their communications with these groups, perhaps in less expensive ways (via SMS). This suggests students continued to use mobile phones after the program, allowing for sustained opportunities to learn.

\section{The Impact of the ABC Program on Household Socio-Economic Outcomes}

While the previous results suggest that the short-term learning gains of the ABC program persisted two years after the program, a key question for many adult education programs - especially those using technology -- is whether this translates into 
improvements in adults' standard of living. While Aker and Ksoll (2015) found that students in $\mathrm{ABC}$ villages were more likely to grow a diverse set of crops immediately after the program, there were no other observable improvements in household socioeconomic outcomes. Yet, the returns to educational investments may take several years to manifest. As our original experiment did not have a pure control group, we are only able to assess the impact of the $\mathrm{ABC}$ program (as compared with the standard adult education program) on these indicators, rather than the returns to the adult education program alone. As such, we are unable to determine whether the impacts on socioeconomic outcomes are due to increased literacy skills, the increased use of mobile phones or some combination of the two.

Table 6 shows the results of estimating equation (1) on a number of outcomes, including income, assets, food security, savings, agricultural practices and intrahousehold decision-making. As we do not have a full consumption and expenditure module, we are unable to assess the impacts of the $\mathrm{ABC}$ program on welfare, but use these indicators as a proxy. Overall, the results suggest that $\mathrm{ABC}$ students were faring better two years after the program, using a broad variety of indicators. Households in $\mathrm{ABC}$ villages were using more diverse strategies to earn income, such as trade, and were 5 percentage points more likely to own a bike, an expensive asset in Niger (Panel A). These differences are statistically significant at the 5 percent level.

Turning to other outcomes, $\mathrm{ABC}$ households were also less likely to experience food insecurity (Panel B): Households reported being 5 percentage points less likely to go hungry frequently over the past year, and $\mathrm{ABC}$ households were 10 percentage points more likely to consume 6 food groups (out of 12) over the past 24 hours, a key threshold 
for improved nutritional status. While these measures are problematic, as they are selfreported, they provide additional evidence of improvements in household well-being.

These improvements in asset ownership and food security are also correlated with changes in households' agricultural and savings behavior: $\mathrm{ABC}$ households were more likely to apply fertilizer, as well as produce and sell gombo, a traditional cash crop grown by women. This latter finding is consistent with the short-term results (Aker and Ksoll 2016). ${ }^{9}$ ABC households were also 11 percentage points more likely to belong to a savings group and felt less obligated to share money with friends or family members, a proxy for some control over finances (Panel D). Most of these effects are statistically significant at the 1 or 5 percent levels.

A key interest of many adult education programs is improving women's empowerment (Banerji et al 2015). Panel E assesses the impact of the ABC program on intra-household decision-making, using a composite indicator. Using these measures, the $\mathrm{ABC}$ program did not have longer-term impacts on intra-household decision-making, either for male or female students.

A key question underlying these results is whether the observed results are due to improved learning or increased usage of the mobile phone. While we do not have the data to disentangle these effects, the regressions on mobile phone usage suggest that households were not using the mobile phone for trade or to receive remittances from migrants. Thus, this provides suggestive evidence that some of the observed impacts can be attributed to improved learning via mobile phone instruction, and not only via increased mobile phone usage.

\footnotetext{
${ }^{9}$ As we do not have detailed data on gombo production, the amount sold or sales prices, we are unable to determine whether this led to increases in income earned from the sale of gombo.
} 


\section{Alternative Explanations}

There are potential threats to the validity of the above findings. While there was no differential attrition by $\mathrm{ABC}$ status several years' after the program, it is possible that the ABC program could have changed households' migration patterns, either for the student or for other household members. If $\mathrm{ABC}$ household members were more likely to engage in seasonal off-migration, thereby contributing to household income, this could potentially explain the observed impacts on assets and food security. While this would not invalidate the observed impacts - as these results could be attributed to the $\mathrm{ABC}$ program - it would change the interpretation of our findings. Yet our results suggest that, two years after the program, neither the extensive nor intensive margin of migration differed by ABC status. Thus, this does not appear to be driving the results. ${ }^{10}$

An additional threat to the validity of these findings is spillovers. For example, if students in $\mathrm{ABC}$ villages directly or indirectly affected the learning or socio-economic outcomes of households in non-ABC villages, then this could over or underestimate our effects. While we have no evidence that spillovers occurred, we hypothesize that such spillovers would result in a lower bound of the impact on learning outcomes, although are unable to sign the potential impact of spillovers on other socio-economic outcomes.

\section{Conclusion}

This paper reports the impacts of a mobile phone-enhanced adult education program in Niger two years after the program. Overall, we find that short-term learning gains persisted two years after the program, as students in $\mathrm{ABC}$ villages had higher test scores than their non- $\mathrm{ABC}$ counterparts, although primarily for reading, with heterogeneous

\footnotetext{
${ }^{10}$ There is no differential attrition between the $\mathrm{ABC}$ and non-ABC villages, and attriters do not differ along observable dimensions. Thus, we do not feel that differential attrition could be driving the results.
} 
effects for math. These effects are primarily explained by more active mobile phone usage after the end of class, which enabled households to continue practicing their reading skills.

The ABC program also resulted in improvements in households' other socioeconomic outcomes, namely asset ownership, agricultural production, food security and savings behavior. While we are unable to conclusively disentangle whether these improvements are primarily attributed to the improved learning or increased mobile phone usage, they are not due to increased mobile phone ownership, which did not differ between the two groups. In the future, a possible way to disentangle the mechanisms for the observed welfare impacts would be to implement a cross-cutting experiment in which study participants are assigned to one of four groups: a control group, an adult education program, a mobile phone program (without an adult education component) and the $\mathrm{ABC}$ program. Assuming that the mobile phone treatment would not significantly increase educational outcomes in the absence of an adult education program, then any welfare impacts observed in this group would be due to the mobile phone. Nevertheless, in a mobile phone cash transfer program in Niger, Aker et al (2016) found that simply providing a mobile phone (with cash) did not lead to any additional welfare improvements as compared with the cash only treatment.

While many education programs are often plagued by high rates of skills depreciation after the program, these results suggest that simple information technology may be able to temper such depreciation, especially if it can be used in daily life and reinforce the skills learned in class. Nevertheless, such technology must be readily accessible to 
students after the program, and something that they can use themselves - which is not always the case with information technology that is classroom-based. 


\section{References}

Abadzi, Helen. 1994. "What We Know About Acquisition of Adult Literacy: Is There Hope?," In World Bank discussion papers, , ix, 93 p. Washington, D.C.: The World Bank.

Abadzi, Helen. 2013. Literacy for All in 100 Days? A research-based strategy for fast progress in low-income countries," GPE Working Paper Series on Learning No. 7

Aker, Jenny C., Christopher Ksoll and Travis J. Lybbert. October 2012. "Can Mobile Phones Improve Learning? Evidence from a Field Experiment in Niger." American Economic Journal: Applied Economics. Vol 4(4): 94-120.

Aker, Jenny C. and Christopher Ksoll. 2016. "Can Mobile Phones Improve Agricultural Outcomes? Evidence from a Randomized Experiment in Niger." Food Policy. Volume 60.

Andrabi, Tahir, Jishnu Das, Asim Ijaz Khwaja, and Tristan Zajonc. 2011. "Do Value-Added Estimates Add Value? Accounting for Learning Dynamics." American Economic Journal: Applied Economics, 3(3): 29-54.

Banerjee, Abhijit, Shawn Cole, Esther Duflo and Leigh Linden. 2007. "Remedying Education: Evidence from Two Randomized Experiments in India." The Quarterly Journal of Economics, 122(3), pp. 1235-64.

Banerji, R., James Berry and Marc Shotland. 2015. "The Impact of Mother Literacy and Participation Programs on Child Learning: A Randomized Evaluation in India."

Barrow, Lisa, Lisa Markman and Cecilia Elena Rouse. 2009. "Technology's Edge: The Educational Benefits of Computer-Aided Instruction." American Economic Journal: Economic Policy, 1(1), pp. 52-74.

Beuermann, Diether, Julian Cristia, Santiago Cueto, Ofer Malamud, and Yyannu Cruz-Aguayo. 2015. "One Laptop per Child at Home: Short-Term Impacts from a Randomized Experiment in Peru." American Economic Journal: Applied Economics. 7(2): 53-80

Blunch, Niels-Hugo and Claus C. Pörtner. 2011. "Literacy, Skills and Welfare: Effects of Participation in Adult Literacy Programs." Economic Development and Cultural Change. Vol. 60, No. 1 (October 2011): 17-66.

Carron, G. 1990. "The Functioning and Effects of the Kenya Literacy Program." African Studies Review, pp. 97-120. 
Case, Anne. 2005. "The Primacy of Education," In Understanding Poverty, ed. Abhijit Vinayak Banerjee, Roland Benabou and Dilip Mookherjee. Oxford ; New York: Oxford University Press.

De Grip, A. and J. Van Loo. 2002. "The Economics of Skills Obsolescence: A Review," In Research in Labor Economics, ed. J. Van Loo and K. Mayhew, 1-25.

\section{Deshpande et al 2017.}

DiNardo, J., J. McCrary, and L. Sanbonmatsu. 2006. "Constructive Proposals for Dealing with Attrition: An Empirical Example." Working paper, University of Michigan.

Lai, F., Luo, R., Zhang, L., Huang, X. and Rozelle, S. 2011. "Does Computer-Assisted Learning Improve Learning Outcomes? Evidence from a Randomized Experiment in Migrant Schools in Beijing." REAP working paper.

Linden, Leigh. 2008. "Complement or substitute? The effect of technology on student achievement in India." JPAL Working Paper.

Mo, D., Zhang, L., Wang, J., Huang, W., Shi, Y., Boswell, M., et al. (2014). The persistence of gains in learning from computer assisted learning (CAL): Evidence from a randomized experiment in rural schools in Shaanxi province in China. REAP working paper.

Ortega, Daniel and Francisco Rodríguez. 2008. "Freed from Illiteracy? A Closer Look at Venezuela's Mision Robinson Literacy Campaign." Economic Development and Cultural Change, 57, pp. 1-30.

Osorio, Felipe, and Leigh L. Linden. 2009. "The use and misuse of computers in education: evidence from a randomized experiment in Colombia." The World Bank Policy Research Working Paper Series.

Oxenham, John, Abdoul Hamid Diallo, Anne Ruhweza Katahoire, Anne PetkovaMwangi and Oumar Sall. 2002. Skills and Literacy Training for Better Livelihoods: A Review of Approaches and Experiences. Washington D.C.: World Bank.

Petrin, A. and K. Train (2002). Omitted product attributes in discrete choice models. Working Paper, Department of Economics, University of California, Berkeley, http://elsa.berkeley.edu/wp/train1202.pdf.

Romain, R. and L. Armstrong. 1987. Review of World Bank Operations in Nonformal Education and Training. World Bank, Education and Training Dept., Policy Division. 
UNESCO. 2005. Education for All: Global Monitoring Report. Literacy for Life. Paris: UNESCO.

UNESCO. 2008. International Literacy Statistics: A Review of Concepts, Methodology and Current Data. Montreal: UNESCO Institute for Statistics.

UNESCO. 2012. Education for All: Global Monitoring Report. Youth and Skills: Putting Education to Work. Paris: UNESCO. 


\section{Table 1A: Baseline Means Comparison for Dosso}

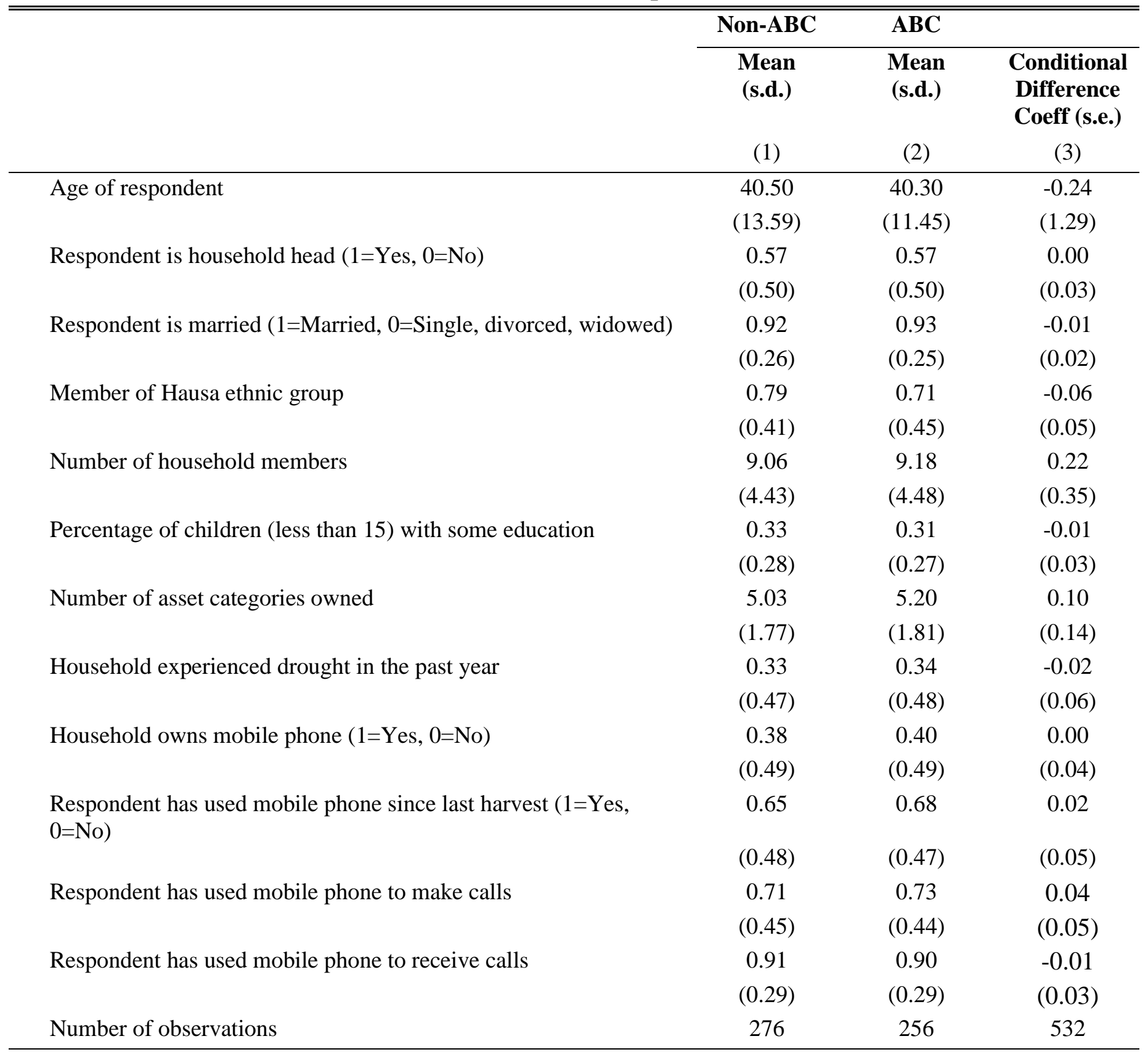

Notes: Column 1 presents the unconditional mean for $\mathrm{ABC}$ villages, Column 2 presents the unconditional mean for non-ABC villages. Column 3 reports the coefficient from a regression of the dependent variable on an indicator variable for $\mathrm{ABC}$ and subregion fixed effects to account for randomization. Thus, Column (3) is not exactly equal to the difference between Columns 1 and 2. Results are robust to omitting the sub-region fixed effects. The sample is a random sample ( 12 households) from among all program participants in each village in the Dosso region, for a total of 532 households. Huber-White standard errors clustered at the village level presented in parentheses. $* * *, * * *$ denote statistical significance at the $1,5,10$ percent levels, respectively. 
Age of respondent

Born in Niger

Respondent is married (1=Married, $0=$ Single, divorced, widowed)

Speak Hausa

Number of household members

Mean age of household members

Mean gender of household members

Number of observations
(1)

(2)

(3)

Difference in Means (Conditional)

ABC

(s.d.)

38.79

(13.02)

0.98

(0.15)

0.91

$(0.29)$

Non-

ABC

Mean

(s.d.)

Coeff (s.e.)

39.23

$-0.43$

(12.96)

(1.18)

0.01

$(0.01)$

$(0.18)$

$-0.03^{*}$

(0.02)

0.88

(0.26)

$-0.03$

(0.32)

0.90

(0.02)

10.51

(0.30)

$-0.41$

(4.37)

11.00

(0.34)

19.77

0.26

(5.03)

(5.60)

(0.37)

0.50

0.50

0.00

(0.14)

(0.14)

562

(0.01)

Notes: Column 1 presents the unconditional mean for $\mathrm{ABC}$ villages, Column 2 presents the unconditional mean for non-ABC villages. Column 3 reports the coefficient from a regression of the dependent variable on an indicator variable for ABC and sub-region fixed effects to account for randomization. Thus, Column (3) is not exactly equal to the difference between Columns 1 and 2. Results are robust to omitting the sub-region fixed effects. The sample is different from the sample in Table A1, in that it is a random sample of 16 households per village from among all program participants in each village in the Dosso region. Huber-White standard errors clustered at the village level presented in parentheses. ***,**, * denote statistical significance at the $1,5,10$ percent levels, respectively. 
Table 2A. Attrition

(1)

(2)

(3)

\begin{tabular}{|c|c|c|c|}
\hline & Non-ABC & $\mathbf{A B C}$ & $\begin{array}{c}\text { Difference in } \\
\text { Means } \\
\text { (Conditional) }\end{array}$ \\
\hline Panel A. Attrition & Mean (s.d.) & Mean (s.d.) & Coeff (s.e.) \\
\hline \multirow[t]{2}{*}{ Attrition } & 0.048 & 0.044 & -0.00 \\
\hline & $(0.21)$ & $(0.21)$ & $(0.01)$ \\
\hline Number of observations & 1719 & 1693 & \\
\hline \multicolumn{4}{|c|}{ Panel B. Causes of Attrition } \\
\hline \multirow[t]{2}{*}{ Illness } & 0.07 & 0.04 & -0.04 \\
\hline & $(0.26)$ & $(0.20)$ & $(0.05)$ \\
\hline \multirow[t]{2}{*}{ Migration } & 0.40 & 0.44 & 0.07 \\
\hline & $(0.50)$ & $(0.50)$ & $(0.08)$ \\
\hline \multirow[t]{2}{*}{ Death } & 0.20 & 0.12 & -0.09 \\
\hline & $(0.40)$ & $(0.32)$ & $(0.06)$ \\
\hline \multirow[t]{2}{*}{$\begin{array}{l}\text { Other (visiting friends, } \\
\text { baptism) }\end{array}$} & 0.29 & 0.34 & 0.04 \\
\hline & $(0.46)$ & $(0.48)$ & $(0.10)$ \\
\hline Number of observations & 83 & 77 & \\
\hline \multicolumn{4}{|c|}{$\begin{array}{l}\text { Notes: Column } 1 \text { presents the unconditional mean for } \mathrm{ABC} \text { villages, Column } 2 \text { presents the } \\
\text { unconditional mean for non-ABC villages. Column } 3 \text { reports the coefficient from a regression of the } \\
\text { dependent variable on an indicator variable for } \mathrm{ABC} \text { and sub-region fixed effects to account for } \\
\text { randomization. Thus, Column (3) is not exactly equal to the difference between Columns } 1 \text { and } 2 \text {. } \\
\text { Results are robust to omitting the sub-region fixed effects. Huber-White standard errors clustered at the } \\
\text { village level presented in parentheses. }{ }^{* *}, * *, * \text { denote statistical significance at the } 1,5,10 \text { percent } \\
\text { levels, respectively. }\end{array}$} \\
\hline
\end{tabular}


Table 2B. Determinants of Attrition

\begin{tabular}{lc}
\hline \hline & Coeff (s.e.) \\
ABC & 0.00 \\
& $(0.01)$ \\
Age & $-0.00 * *$ \\
& $(0.00)$ \\
Female & -0.01 \\
& $(0.01)$ \\
Doutchi & $0.03 * * *$ \\
& $(0.01)$ \\
Number of Observations & 3137 \\
R-squared & 0.006 \\
P-value of joint F-test & 0.03 \\
\hline
\end{tabular}

Notes: This table estimates a regression of attrition on a variety of covariates. The sample consists of all of the program participants (50 per village) from the original $\mathrm{ABC}$ program in each village in the Dosso region. Huber-White standard errors clustered at the village level presented in parentheses. $* * *, * * *$ denote statistical significance at the $1,5,10$ percent levels, respectively. 
Table 3A. Medium-Term Impact of the ABC Program on Reading Scores

\begin{tabular}{|c|c|c|c|c|c|c|}
\hline & (1) & (2) & (3) & (4) & (5) & (6) \\
\hline & Any Word Read & $\begin{array}{c}\text { Number of } \\
\text { Words } \\
\text { Read } \\
\end{array}$ & $\begin{array}{c}\text { Z-Score } \\
\text { Number of } \\
\text { Words Read } \\
\end{array}$ & $\begin{array}{c}\text { Z-Score Number } \\
\text { of Words } \\
\text { Read/Second }\end{array}$ & $\begin{array}{c}\text { Reading } \\
\text { Comprehension }\end{array}$ & $\begin{array}{c}\text { Original } \\
\text { Reading } \\
\text { Level (0-7) }\end{array}$ \\
\hline \multicolumn{7}{|l|}{ Panel A: All Students } \\
\hline ABC Village & $\begin{array}{c}0.08 * * \\
(0.03)\end{array}$ & $\begin{array}{c}2.43 * * \\
(1.18)\end{array}$ & $\begin{array}{c}0.15^{* *} * \\
(0.07)\end{array}$ & $\begin{array}{c}0.12 \\
(0.08)\end{array}$ & $\begin{array}{c}0.13 \\
(0.09)\end{array}$ & $\begin{array}{c}0.43 * * \\
(0.19)\end{array}$ \\
\hline Female & Yes & Yes & Yes & Yes & Yes & Yes \\
\hline 2010 Cohort & Yes & Yes & Yes & Yes & Yes & Yes \\
\hline $\begin{array}{l}\text { Strata Fixed Effects } \\
\text { Mean of Non-ABC }\end{array}$ & Yes & Yes & Yes & Yes & Yes & Yes \\
\hline Villages & 0.27 & 7.28 & 0 & 0 & 0.77 & 1.71 \\
\hline Number of observations & 1,124 & 1,124 & 1,124 & 1,124 & 1,124 & 1,124 \\
\hline R-squared & 0.12 & 0.12 & 0.11 & 0.12 & 0.12 & 0.12 \\
\hline \multicolumn{7}{|l|}{ Panel B: Gender } \\
\hline ABC Village & $\begin{array}{c}0.07 \\
(0.04)\end{array}$ & $\begin{array}{c}2.28 \\
(1.91)\end{array}$ & $\begin{array}{c}0.14 \\
(0.12)\end{array}$ & $\begin{array}{c}0.10 \\
(0.12)\end{array}$ & $\begin{array}{c}0.07 \\
(0.16)\end{array}$ & $\begin{array}{c}0.35 \\
(0.27)\end{array}$ \\
\hline ABC*Female & $\begin{array}{c}0.03 \\
(0.06)\end{array}$ & $\begin{array}{c}0.28 \\
(2.18)\end{array}$ & $\begin{array}{c}0.02 \\
(0.14)\end{array}$ & $\begin{array}{c}0.05 \\
(0.14)\end{array}$ & $\begin{array}{c}0.09 \\
(0.18)\end{array}$ & $\begin{array}{c}0.22 \\
(0.35)\end{array}$ \\
\hline Female & $\begin{array}{c}-0.24 * * * \\
(0.04)\end{array}$ & $\begin{array}{c}-9.24 * * * \\
(1.30)\end{array}$ & $\begin{array}{c}-0.58 * * * \\
(0.08)\end{array}$ & $\begin{array}{c}-0.53 * * * \\
(0.08)\end{array}$ & $\begin{array}{c}-0.91 * * * \\
(0.12)\end{array}$ & $\begin{array}{c}-1.52 * * * \\
(0.24)\end{array}$ \\
\hline 2010 Cohort & Yes & Yes & Yes & Yes & Yes & Yes \\
\hline Strata Fixed Effects & Yes & Yes & Yes & Yes & Yes & Yes \\
\hline Number of observations & 1,124 & 1,124 & 1,124 & 1,124 & 1,124 & 1,124 \\
\hline R-squared & 0.12 & 0.11 & 0.12 & 0.11 & 0.11 & 0.12 \\
\hline
\end{tabular}




\begin{tabular}{|c|c|c|c|c|c|c|}
\hline \multicolumn{7}{|l|}{ Panel C: Age } \\
\hline \multirow[t]{2}{*}{ ABC Village } & 0.04 & 1.27 & 0.08 & 0.07 & 0.04 & 0.21 \\
\hline & $(0.04)$ & $(1.37)$ & $(0.09)$ & $(0.09)$ & $(0.12)$ & $(0.23)$ \\
\hline \multirow[t]{2}{*}{$\mathrm{ABC} *$ Young } & 0.07 & 1.67 & 0.11 & 0.07 & 0.10 & 0.41 \\
\hline & $(0.05)$ & $(1.79)$ & $(0.11)$ & $(0.12)$ & $(0.17)$ & $(0.29)$ \\
\hline \multirow[t]{2}{*}{ Young $(<=39$ years $)$} & $0.15^{* * *}$ & $4.94 * * *$ & $0.31 * * *$ & $0.29 * * *$ & $0.36 * * *$ & $0.76 * * *$ \\
\hline & $(0.04)$ & $(1.06)$ & $(0.07)$ & $(0.07)$ & $(0.12)$ & $(0.20)$ \\
\hline Female & Yes & Yes & Yes & Yes & Yes & Yes \\
\hline 2010 Cohort & Yes & Yes & Yes & Yes & Yes & Yes \\
\hline Strata Fixed Effects & Yes & Yes & Yes & Yes & Yes & Yes \\
\hline Number of observations & 1,124 & 1,124 & 1,124 & 1,124 & 1,124 & 1,124 \\
\hline R-squared & 0.12 & 0.12 & 0.11 & 0.12 & 0.11 & 0.12 \\
\hline
\end{tabular}


Table 3B. Impact of ABC on Math Scores

\begin{tabular}{|c|c|c|c|c|c|c|}
\hline & (1) & (2) & (3) & (4) & (5) & (6) \\
\hline & $\begin{array}{l}\text { Numbers } \\
\text { correctly } \\
\text { identified } \\
\text { (out of } 20 \text { ) }\end{array}$ & $\begin{array}{c}\text { Z-Score } \\
\text { Number } \\
\text { Identification }\end{array}$ & $\begin{array}{c}\text { Oral Addition } \\
\text { and } \\
\text { Subtraction }\end{array}$ & $\begin{array}{l}\text { Z-Score of } \\
\text { Addition } \\
\text { and } \\
\text { Subtraction }\end{array}$ & $\begin{array}{c}\text { Math } \\
\text { Composite } \\
\text { Z-Score }\end{array}$ & $\begin{array}{c}\text { Original } \\
\text { Math Level } \\
(0-7)\end{array}$ \\
\hline \multicolumn{7}{|l|}{ Panel A: All Students } \\
\hline \multirow[t]{2}{*}{ ABC Village } & 0.80 & 0.10 & 0.17 & 0.08 & 0.10 & 0.25 \\
\hline & $(0.54)$ & $(0.07)$ & $(0.13)$ & $(0.06)$ & $(0.07)$ & $(0.16)$ \\
\hline Female & Yes & Yes & Yes & Yes & Yes & Yes \\
\hline 2010 Cohort & Yes & Yes & Yes & Yes & Yes & Yes \\
\hline Strata Fixed Effects & Yes & Yes & Yes & Yes & Yes & Yes \\
\hline \multicolumn{7}{|l|}{ Mean of Non-ABC } \\
\hline Villages & 11.45 & 0 & 7.7 & 0 & 0 & 2.59 \\
\hline Number of observations & 1,124 & 1,124 & 1,124 & 1,124 & 1,124 & 1,124 \\
\hline R-squared & 0.29 & 0.12 & 0.14 & 0.32 & 0.28 & 0.14 \\
\hline \multicolumn{7}{|l|}{ Panel B: Gender } \\
\hline \multirow[t]{2}{*}{ ABC Village } & 0.02 & 0.00 & -0.00 & -0.00 & 0.01 & -0.01 \\
\hline & $(0.58)$ & $(0.07)$ & $(0.16)$ & $(0.07)$ & $(0.07)$ & $(0.04)$ \\
\hline \multirow[t]{2}{*}{ ABC*Female } & $1.56^{*}$ & $0.20 *$ & 0.34 & 0.16 & 0.18 & 0.09 \\
\hline & $(0.87)$ & $(0.11)$ & $(0.30)$ & $(0.15)$ & $(0.12)$ & $(0.08)$ \\
\hline \multirow[t]{2}{*}{ Female } & $-8.57 * * *$ & $-1.08 * * *$ & $-1.15^{* * *}$ & $-0.55 * * *$ & $-1.04 * * *$ & $-0.18 * * *$ \\
\hline & $(0.56)$ & $(0.07)$ & $(0.21)$ & $(0.10)$ & $(0.08)$ & $(0.06)$ \\
\hline 2010 Cohort & Yes & Yes & Yes & Yes & Yes & Yes \\
\hline Strata Fixed Effects & Yes & Yes & Yes & Yes & Yes & Yes \\
\hline Number of observations & 1,124 & 1,124 & 1,124 & 1,124 & 1,124 & 1,111 \\
\hline R-squared & 0.29 & 0.29 & 0.12 & 0.12 & 0.28 & 0.14 \\
\hline
\end{tabular}




\begin{tabular}{lcccccc} 
Panel C: Age & \multicolumn{1}{c}{ Ag } & & & \\
ABC Village & -0.08 & -0.01 & -0.02 & -0.01 & -0.01 & 0.01 \\
& $(0.63)$ & $(0.08)$ & $(0.19)$ & $(0.09)$ & $(0.08)$ & $(0.20)$ \\
ABC*Young & $1.38^{*}$ & $0.17^{*}$ & 0.34 & 0.16 & $0.17^{*}$ & $0.47^{*}$ \\
& $(0.78)$ & $(0.10)$ & $(0.21)$ & $(0.10)$ & $(0.10)$ & $(0.25)$ \\
Young (<=35 years) & $2.65^{* * *}$ & $0.34^{* * *}$ & 0.23 & 0.11 & $0.34^{* * *}$ & 0.13 \\
& $(0.53)$ & $(0.07)$ & $(0.15)$ & $(0.07)$ & $(0.07)$ & $(0.17)$ \\
Female & Yes & Yes & Yes & Yes & Yes & Yes \\
2010 Cohort & Yes & Yes & Yes & Yes & Yes & Yes \\
Strata Fixed Effects & Yes & Yes & Yes & Yes & Yes & Yes \\
Number of observations & 1,124 & 1,124 & 1,124 & 1,124 & 1,120 & 1,124 \\
R-squared & 0.33 & 0.33 & 0.13 & 0.13 & 0.33 & 0.1 \\
\hline
\end{tabular}

Notes: This table estimates the impact of the $\mathrm{ABC}$ program on a variety of math indicators. $\mathrm{ABC}$ is equal to 1 if the student lived in a ABC village between 2009 and 2011, 0 otherwise. All regressions control for cohort and randomization fixed effects. Huber-White standard errors clustered at the village level are in parentheses. 
Table 4. Skills Depreciation

(1)

Reading Level Any Word Read
(2)

(3)

Panel A: OLS

\begin{tabular}{|c|c|c|c|}
\hline $\mathrm{ABC}$ & $\begin{array}{c}0.24 \\
(0.16)\end{array}$ & $\begin{array}{l}0.05 * \\
(0.03)\end{array}$ & $\begin{array}{c}0.13 \\
(0.15)\end{array}$ \\
\hline Lagged Score (2011) & $\begin{array}{c}0.76 * * * \\
(0.04)\end{array}$ & $\begin{array}{c}0.37 * * * \\
(0.03)\end{array}$ & $\begin{array}{c}0.30 * * * \\
(0.05)\end{array}$ \\
\hline Female & $\begin{array}{c}-0.60 * * * \\
(0.16)\end{array}$ & $\begin{array}{c}-0.15 * * * \\
(0.03)\end{array}$ & $\begin{array}{c}-0.93 * * * \\
(0.15)\end{array}$ \\
\hline Cohort 2010 & $\begin{array}{l}-0.05 \\
(0.15)\end{array}$ & $\begin{array}{l}-0.05^{*} \\
(0.03)\end{array}$ & $\begin{array}{l}-0.15 \\
(0.15)\end{array}$ \\
\hline Strata Fixed Effects & Yes & Yes & Yes \\
\hline Number of observations & 930 & 930 & 928 \\
\hline R-squared & 0.41 & 0.26 & 0.14 \\
\hline \multicolumn{4}{|c|}{ Panel B: Control Function Approach } \\
\hline $\mathrm{ABC}$ & $\begin{array}{l}0.51 * * \\
(0.22)\end{array}$ & $\begin{array}{l}0.07 * * \\
(0.03)\end{array}$ & $\begin{array}{c}0.22 \\
(0.15)\end{array}$ \\
\hline $\begin{array}{l}\text { Residual of Lagged Scor } \\
\text { (2011) }\end{array}$ & $\begin{array}{c}0.73 * * * \\
(0.05)\end{array}$ & $\begin{array}{c}0.36 * * * \\
(0.03)\end{array}$ & $\begin{array}{c}0.30 * * * \\
(0.05)\end{array}$ \\
\hline Female & $\begin{array}{c}-0.63 * * * \\
(0.16)\end{array}$ & $\begin{array}{c}-0.15 * * * \\
(0.03)\end{array}$ & $\begin{array}{c}-0.93 * * * \\
(0.15)\end{array}$ \\
\hline Cohort 2010 & $\begin{array}{l}-0.44^{*} \\
(0.23)\end{array}$ & $\begin{array}{c}-0.08 * * \\
(0.03)\end{array}$ & $\begin{array}{l}-0.18 \\
(0.16)\end{array}$ \\
\hline Strata Fixed Effects & Yes & Yes & Yes \\
\hline Number of observations & 930 & 930 & 929 \\
\hline
\end{tabular}

Notes: This table estimates the impact of the $\mathrm{ABC}$ program on a variety of reading and math indicators. ABC is equal to 1 if the student lived in a ABC village between 2009 and 2011, 0 otherwise. Panel A uses OLS, whereas Panel B includes the residuals from the first stage regression of 2011 test scores on village-level fixed effects as an additional control. All regressions control for cohort and randomization fixed effects. Huber-White standard errors clustered at the village level are in parentheses. 
(1)

(2)

Mean

(s.d.) Coeff (s.e.)

Used mobile phone since last harvest

0.9

0.02

$(0.31)$

(0.02)

Amount spent on mobile phone in past two weeks (CFA)

670

9.57

(1609)

(96.49)

Made call

0.75

$(0.43)$

$0.07 * * *$

Received call

0.96

$(0.20)$

0.06

$(0.24)$

Received SMS

0.24

$(0.43)$

Transferred airtime

0.23

$(0.42)$

Received airtime

0.37

(0.48)

0.93

(0.26)

0.09

(0.29)
(0.02)

0.01

(0.01)

$0.06 * *$

(0.03)

$0.10 * * *$

(0.03)

$0.08 * * *$

(0.03)

$0.09 * * *$

$(0.03)$

0.03 *

$(0.02)$

0.02

(0.03)

Notes: This table estimates the impact of the $\mathrm{ABC}$ program on a variety of outcomes related to mobile phone ownership and usage. $\mathrm{ABC}$ is equal to 1 if the student lived in a $\mathrm{ABC}$ village between 2009 and 2011, 0 otherwise. All regressions control for cohort and randomization fixed effects. Huber-White standard errors clustered at the village level are in parentheses. 


\section{Table 6. Household-Level Welfare Outcomes}

\begin{tabular}{lcc}
\hline \hline & $(1)$ & $(2)$ \\
& Mean & Coeff (s.e.) \\
\cline { 2 - 3 } Panel A: Income Sources and Asset Ownership & $($ s.d.) & \\
Number of income sources (out of 12) & 3.91 & $0.15^{* *}$ \\
& $(1.26)$ & -0.07 \\
Household engaged in trade (0/1) & 0.69 & $0.06^{* *}$ \\
& $(0.46)$ & $(0.03)$ \\
Household had a migrant & 0.65 & -0.05 \\
& $(0.48)$ & $(0.03)$ \\
Z-score of number of household assets categories owned per capita & 0.00 & 0.12 \\
Bike ownership (0/1) & $(1.00)$ & $(0.08)$ \\
Plow ownership (0/1) & 0.13 & $0.05 * *$ \\
Mobile phone ownership (0/1) & $(0.34)$ & $(0.02)$ \\
& 0.24 & -0.00
\end{tabular}

Panel B: Food Security

Household went a day without food in past year (0/1)

$0.28-0.02$

Household went without food sometimes/frequently (1) or rarely (0) in past

year

$(0.45)$

$(0.04)$

$0.2-0.05 *$

$(0.40) \quad(0.03)$

Household diet diversity (out of 12) 


\begin{tabular}{|c|c|c|}
\hline Reached household diet diversity threshold of 6 & $\begin{array}{c}0.31 \\
(0.46) \\
\end{array}$ & $\begin{array}{l}0.10^{*} \\
(0.06)\end{array}$ \\
\hline \multicolumn{3}{|l|}{ Panel C: Agriculture and Agricultural Practices } \\
\hline Number of crops produced & $\begin{array}{c}6.35 \\
(1.53)\end{array}$ & $\begin{array}{c}0.16 \\
(0.14)\end{array}$ \\
\hline Number of crops sold & $\begin{array}{c}3.21 \\
(0.18)\end{array}$ & $\begin{array}{c}0.28 \\
(0.18)\end{array}$ \\
\hline Gombo produced & $\begin{array}{c}0.63 \\
(0.48)\end{array}$ & $\begin{array}{l}0.06^{*} \\
(0.03)\end{array}$ \\
\hline Vegetables produced & $\begin{array}{c}0.29 \\
(0.45)\end{array}$ & $\begin{array}{c}0.09 \\
(0.06)\end{array}$ \\
\hline Gombo sold & $\begin{array}{c}0.17 \\
(0.38)\end{array}$ & $\begin{array}{c}0.11 * * \\
(0.04)\end{array}$ \\
\hline Vegetables sold & $\begin{array}{c}0.63 \\
(0.48)\end{array}$ & $\begin{array}{c}0.06 \\
(0.08)\end{array}$ \\
\hline Fertilized used & $\begin{array}{c}0.51 \\
(0.50)\end{array}$ & $\begin{array}{l}0.07 * \\
(0.04)\end{array}$ \\
\hline Improved seeds used & $\begin{array}{c}0.39 \\
(0.50)\end{array}$ & $\begin{array}{c}0.00 \\
(0.03)\end{array}$ \\
\hline Irrigation used & $\begin{array}{c}0.19 \\
(0.40) \\
\end{array}$ & $\begin{array}{c}0.06 \\
(0.04) \\
\end{array}$ \\
\hline \multicolumn{3}{|l|}{ Panel D: Savings and Risk Preferences } \\
\hline Belonged to a savings group & $\begin{array}{c}0.35 \\
(0.48)\end{array}$ & $\begin{array}{c}0.11 * * * \\
(0.04)\end{array}$ \\
\hline Number of different savings mechanisms used & $\begin{array}{c}3.03 \\
(1.14)\end{array}$ & $\begin{array}{c}0.08 \\
(0.06)\end{array}$ \\
\hline
\end{tabular}


Would like to spend less

$\begin{array}{cc}0.45 & 0.09 * * * \\ (0.49) & (0.03) \\ 0.90 & -0.04 * * \\ (0.31) & (0.02) \\ 0.81 & -0.03 \\ (0.39) & (0.03) \\ 0.68 & 0.01 \\ (0.46) & (0.02)\end{array}$

Obligated to share money with a friend or family member

0.00

Panel E: Intra-Household Decision-Making

Z-score of index of autocratic decision-making

$-0.04$

$(0.04)$

Notes: This table estimates the impact of the $\mathrm{ABC}$ program on a variety of outcomes related to household well-being. $\mathrm{ABC}$ is equal to 1 if the student lived in a $\mathrm{ABC}$ village between 2009 and 2011, 0 otherwise. All regressions control for cohort and randomization fixed effects. Huber-White standard errors clustered at the village level are in parentheses. 